\title{
A novel organ preservation solution with efficient clearance of red blood cells improves kidney transplantation in a canine model
}

\author{
Sheng Wang ${ }^{1 \dagger}$, Kristyn Gumpper ${ }^{2 \dagger}$, Tao Tan², Xianzhang Luo ${ }^{1}$, Hui Guo ${ }^{1}$, Changsheng Ming ${ }^{1}$, Hanying Jiang ${ }^{1,4}$, \\ Jiangguo Fang ${ }^{4}$, Guang Du ${ }^{4}$, Hua Zhu ${ }^{2}$, Jianjie Ma ${ }^{2,3}$, Zhishui Chen ${ }^{1^{*}}$ and Nianqiao Gong ${ }^{{ }^{*}}$
}

\begin{abstract}
Organ preservation solutions are designed to minimize organ damage during transplantation. A novel preservation solution, WMO-II, was developed to have a low viscosity and to improve microvasculature perfusion for kidneys. In an autologous canine transplantation model, kidney function and recovery were evaluated after organs were flushed and cold-stored with WMO-II or HTK solution, a perfusate currently approved for clinical use. The average number of red blood cells remaining in a single glomerulus after flushing with WMO-II was significantly reduced when compared with HTK solution. Additionally, WMO-II reduced the number of apoptotic bodies in stored kidneys compared to HTK treated tissue after $48 \mathrm{~h}$ of cold storage by reducing expression of Caspase-9, BiP, Chop, and Caspase-12. WMO-II solution reduced serum creatinine levels and serum potassium in kidneys stored for $48 \mathrm{~h}$ when compared to HTK perfusion. WMO-II preserves kidney function as evidenced by the reduction in serum creatinine and potassium during graft transplantation.
\end{abstract}

Keywords: Organ preservation solution, Low-viscosity, Protect, Kidney, Graft

\section{Dear Editor,}

Transplantation has become the most effective treatment for patients suffering end-stage organ failure. During transplantation, tissue grafts suffer multiple stresses such as warm and cold ischemia, which are detrimental to early graft function and result in delayed graft function (DGF) or even primary non-function (PNF) [1]. To preserve early graft function, a preservation solution is required for the thorough flushing and cold storage of organs to prevent cell swelling and contracture due to energy loss and ameliorating free radical-induced injury.

\footnotetext{
*Correspondence: zschen@tjh.tjmu.edu.cn; nqgong@tjh.tjmu.edu.cn tSheng Wang and Kristyn Gumpper contribute equally to this work ${ }^{1}$ Institute of Organ Transplantation, Key Laboratory of the Ministry of Health and the Ministry of Education, Tongji Hospital, Tongji Medical College, Huazhong University of Science and Technology, Wuhan 430030, China

Full list of author information is available at the end of the article
}

The severity of ischemic damage is directly correlated with the extent of microcirculatory reperfusion failure [2]. To reduce harm to kidneys from recipient immune reaction, a low-viscosity flush solution may effectively wash out donor blood cells, inflammatory mediators, and vasoactive substances [3]. Over the past several decades, HTK and UW solutions are the most commonly used and are considered effective and safe $[4,5]$. Unfortunately, ischemia injury-induced renal damage with resultant DGF remains relatively high, ranging from 20 to $40 \%$ in transplant recipients [6], suggesting the need for optimizing current available solutions. In addition to a need for optimizing solutions, there is a push to expand the criteria for donors to increase the number of organs available for transplantation. This indicates that there is still a need for optimizing perfusion solutions to reduce the ischemia-induced renal injury.

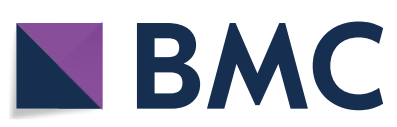

(c) The Author(s) 2018. This article is distributed under the terms of the Creative Commons Attribution 4.0 International License (http://creativecommons.org/licenses/by/4.0/), which permits unrestricted use, distribution, and reproduction in any medium, provided you give appropriate credit to the original author(s) and the source, provide a link to the Creative Commons license, and indicate if changes were made. The Creative Commons Public Domain Dedication waiver (http://creativecommons.org/ publicdomain/zero/1.0/) applies to the data made available in this article, unless otherwise stated. 
Here, we have developed a novel, low-viscosity solution, Wuhan Medical College organ preservation solution-II (WMO-II). In this study, the WMO-II solution was characterized and compared to another low-viscosity preservation solution, HTK. Kidneys were evaluated in an autologous canine transplantation model to assess efficacy on microvasculature perfusion and function without immune interference in both in vivo and ex vivo models.

\section{Results and discussion}

The WMO-II solution we describe was designed by the Institute of Organ Transplantation and the Pharmacy Department of Tongji Hospital, Tongji Medical College, Huazhong University of Science and Technology (Table 1). The product consists of two connected inner bags and an over pouch. The inner bags are separated into Chamber A and Chamber B by a peel-able seal that can be opened with a moderate squeeze to mix solutions A and B (Additional file 1: Figure S1). An oxygen absorber is placed between the inner bag and the over pouch. Based on the components of solutions A and B, the WMO-II solution remains stable when stored at room temperature or $4{ }^{\circ} \mathrm{C}$. Before use, the solution is mixed and cooled to $4{ }^{\circ} \mathrm{C}$.

To assess the potential for the WMO-II solution, we first conducted experiments with ex vivo kidneys derived from dogs. We perfused kidneys with either the WMOII solution or HTK, another low viscosity solution, and assessed clearance of red blood cells from the glomeruli and microvasculature of the kidneys. The H\&E stain in Fig. 1a shows WMO-II greatly reduced the number of red blood cells retained in a single glomerulus compared to HTK. Additionally, the TEM images in Fig. 1b clearly show WMO-II perfused kidneys retained fewer red blood cells in the microvasculature than HTK perfused kidneys. On average, fewer red blood cells were observed in a single glomerulus perfused with WMO-II solution $(3.9 \pm 1.4)$ compared with $8.7 \pm 1.3$ in the HTK group $(P<0.05)$ (Fig. 1c), consistent with our theory that a lower viscosity solution would be more effective at clearing the microvasculature of the kidney. This is particularly important as red blood cells, when lysed due to changes in osmotic pressure or other signals of cell death, release many oxidative species, damaging surrounding tissue. Additionally, complete perfusion of microvasculature can help reduce immunological side effects, an aspect of WMO-II that will be assessed in future studies.

Donated kidneys often undergo a relatively long cold ischemia time (CIT) because kidneys are often transported long distances. If kidneys can stay functional under prolonged CIT, the pool of donors would greatly expand. We designed the WMO-II solution to
Table 1 Composition of WMO-II solution

\begin{tabular}{|c|c|c|c|}
\hline Chamber & Component & $\begin{array}{l}\text { Concentration } \\
\text { (mmol/L) }\end{array}$ & Volume $(\mathrm{mL})$ \\
\hline \multirow[t]{10}{*}{ A } & Potassium citrate & $23.4-28.6$ & \multirow[t]{10}{*}{500} \\
\hline & $\begin{array}{l}\text { Sodiumdi hydrogen } \\
\text { phosphate }\end{array}$ & $3.6-4.4$ & \\
\hline & $\begin{array}{l}\text { Disodium hydrogen } \\
\text { phosphate }\end{array}$ & $22.5-27.5$ & \\
\hline & Magnesium sulfate & $4.5-5.5$ & \\
\hline & Potassium chloride & $1.8-2.2$ & \\
\hline & Mannitol & $143-158$ & \\
\hline & Adenosine & $4.5-5.5$ & \\
\hline & Acetyl cysteine & $4.3-5.8$ & \\
\hline & Sodium hydroxide & $4.3-5.8$ & \\
\hline & Water for injection & & \\
\hline \multirow[t]{2}{*}{ B } & Dextran 40 & - & \multirow[t]{2}{*}{500} \\
\hline & Water for injection & & \\
\hline
\end{tabular}

incorporate more antioxidants to reduce the amount of cellular damage caused by the oxidative stress associated with CIT. In comparison with HTK, WMO-II does not use histidine, due to histidine's propensity for enhancing the formation of reactive oxygen species for cell injury [7] and augments mannitol since it removes reactive oxygen species as a sugar alcohol. Additionally, WMO-II contains adenosine, acetylcysteine and dextran for prevention of free radicals. Adenosine prevents tissue damage during instances of hypoxia and ischemia [8]; acetylcysteine is a medication that is used to loosen thick mucus and helps reduce viscosity of the WMO-II solution [9]; and dextran is a complex branched glucan used to reduce blood viscosity, decreasing vascular thrombosis by reducing erythrocyte aggregation, and decreasing platelet adhesiveness [10]. These components result in less apoptosis by decreasing mitochondrial and ER stress. Imaging indicated only a few apoptotic tubular cells in kidneys treated with either WMO-II or HTK solutions for 12 and $24 \mathrm{~h}$ (Fig. 2a). The number of apoptotic tubular cells increased greatly in both the WMO-II $(48 \mathrm{~h})$ group and HTK $(48 \mathrm{~h})$ group. Excitingly, at $48 \mathrm{~h}$, WMO-II perfusion reduced the amount of apoptotic tubular cells when compared to the HTK perfusion $(22.87 \pm 1.52$ vs. $29.17 \pm 5.34, P<0.05)$ (Fig. $2 b)$. The Fasmediated (Fas), mitochondrial-mediated (Caspase-9), and ERS-mediated (BiP, Chop, and Caspase-12) pathways were examined using western blot analysis (Fig. 3a). Normal kidney tissue was compared with kidneys stored in the WMO-II or HTK solutions for 12, 24 and $48 \mathrm{~h}$. As shown in Fig. 3b, there were, on average, no significant differences in the expression of Fas between the WMO-II and HTK groups. However, expression of Caspase-9 was 

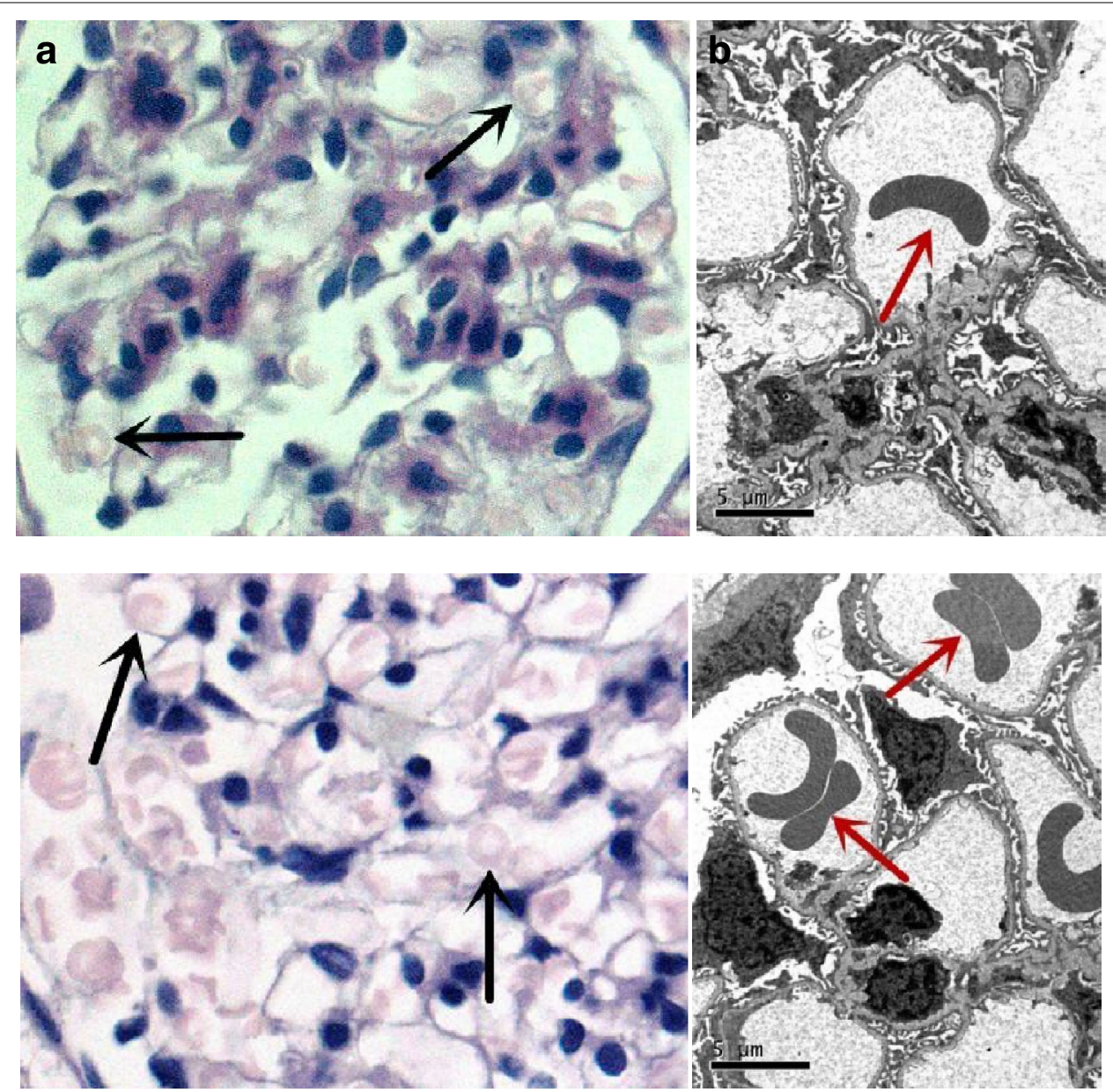

C The number of retaining red blood cells in glomerular

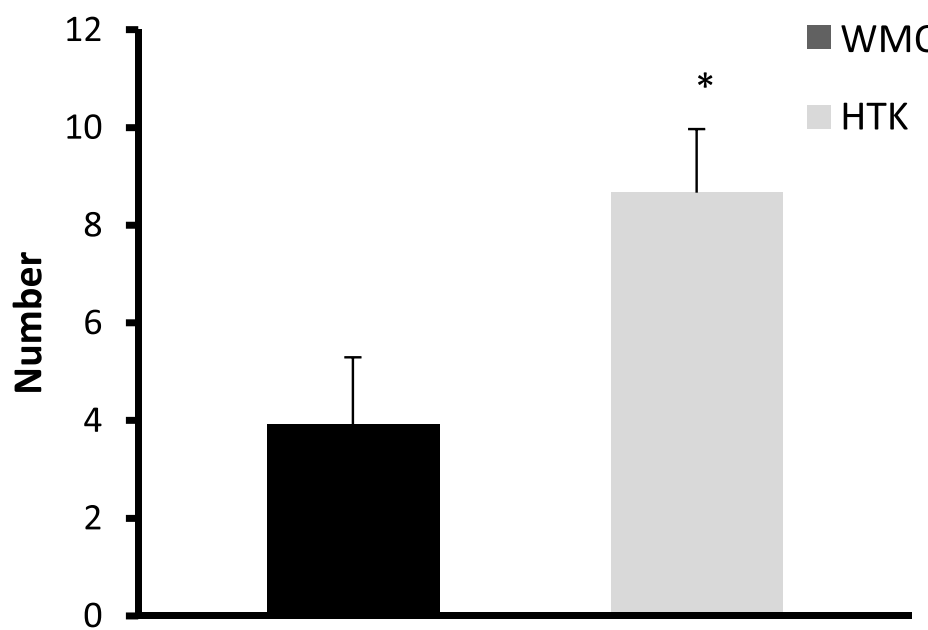

Fig. 1 Perfusion with WMO-II improves clearance of red blood cells in kidneys. a Representative images of H\&E staining of ex vivo canine kidneys flushed with $150 \mathrm{~mL}$ either solution at $4{ }^{\circ} \mathrm{C}$ via the artery for $5 \mathrm{~min}$ or until the effluent ran clear. Black arrows: retained red blood cells. b Representative TEM images of a single glomeruli of ex vivo canine kidneys after perfusion with WMO-II or HTK solutions. Red arrows: retained red blood cells. $\mathbf{c}$ The average number of blood red cells retained in a single glomerulus after perfusion with WMO-II or HTK solutions. Each kidney was prepared in 2 sections $(1 \mathrm{~cm} \times 1 \mathrm{~cm})$ and all glomeruli in each section were examined. Data expressed as mean with standard error. $n=6 * P<0.05$ 


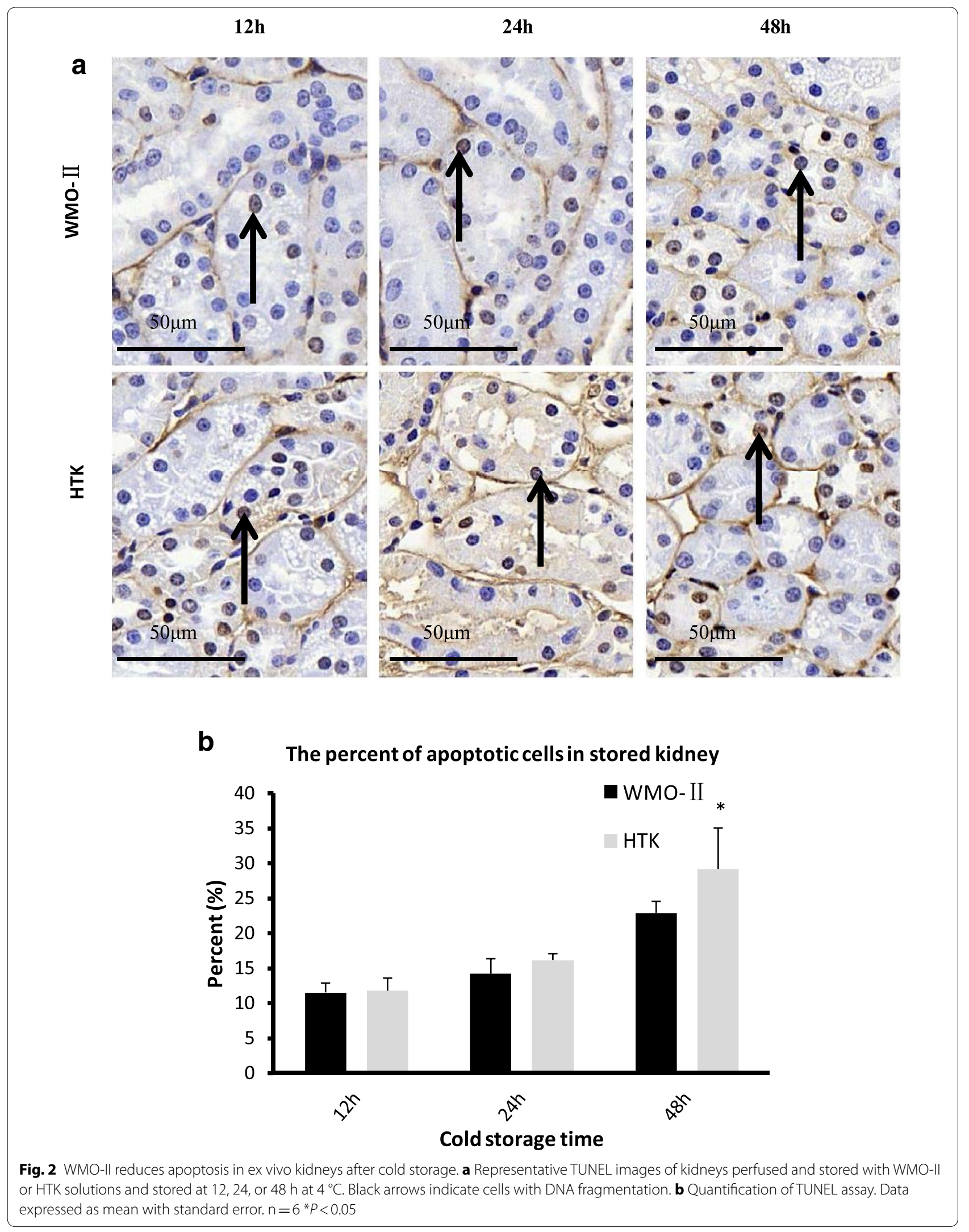




\section{$12 \mathrm{~h} \quad 24 \mathrm{~h} \quad 48 \mathrm{~h}$}

a Normal WMO-II HTK WMO-II HTK WMO-II HTK

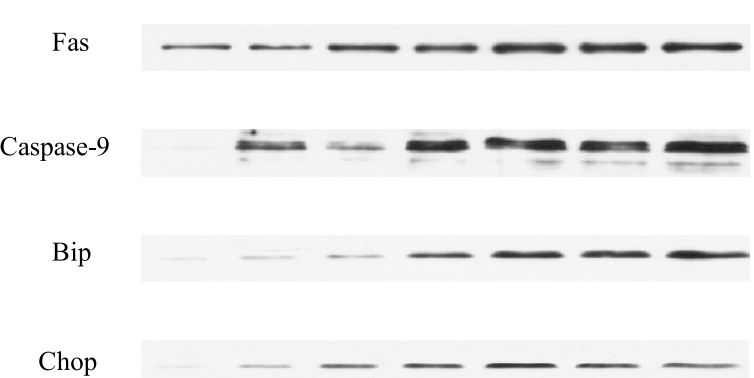

Caspase-12 - - - - -

Actin
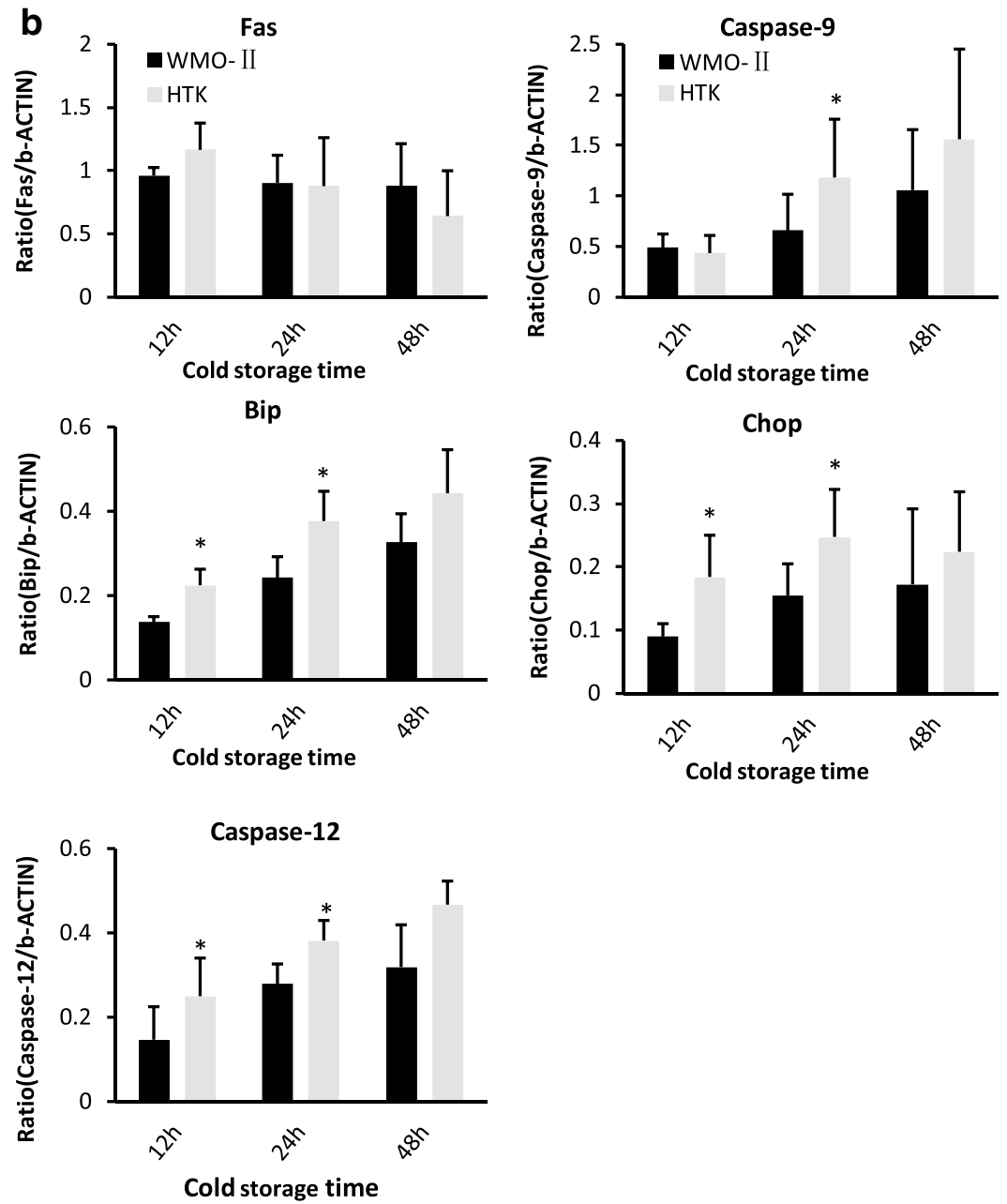

Fig. 3 WMO-II prevents apoptosis by down-regulating mitochondrial and ERS-mediated apoptotic signaling. a Representative western blot images of Fas, Caspase-9, BiP, CHOP, Caspase-12, and $\beta$-Actin from tissues perfused and stored with WMO-II or HTK solutions for 12, 24, or 48 h. b Western blot signal quantification via AlphaEaseFC ${ }^{\mathrm{TM}}$ software and normalized to $\beta$-actin signal. Data expressed as mean with standard error. $\mathrm{n}=6 * P<0.05$ 
lower $(P<0.05)$ in the WMO-II $(24 \mathrm{~h})$ group than in the HTK (24 h) group. Moreover, expression of BiP, Chop, and Caspase-12 were lower $(P<0.05)$ in the WMO-II $(12$ and $24 \mathrm{~h}$ ) group than their counterparts in the HTK (12 and $24 \mathrm{~h}$ ) group. Although causation of a reduction in red blood cells causing decrease in in damage is not proven in this study, there was a significant reduction in apoptotic cell bodies in kidneys treated with WMO-II solution with a concurrent decrease in mitochondrial and ERSmediated apoptosis markers which could be attributed to either a reduction in red blood cell retention or inhibition of oxidative species with the anti-oxidant properties of the solution.

In addition to assessing cell viability after CIT, a new perfusate would be useless if it did not also improve tissue function after transplantation. An auto-transplantation model was used to test the renal protective effect of the WMO-II solution in an antigen-independent model. Animals were randomly assigned to groups designated by preservation solution (WMO-II and HTK) and cold storage time [12 h $(\mathrm{n}=5), 24 \mathrm{~h}(\mathrm{n}=10)$, and $48 \mathrm{~h}(\mathrm{n}=10)]$. The recipient animals were monitored for up to 10 days to assess kidney function by serum creatinine ( $\mathrm{SCr}$ ) and potassium $\left(\mathrm{K}^{+}\right)$concentrations.

In the first group, the kidneys were stored for $12 \mathrm{~h}$, resulting in minimum damage to the kidney, as shown in Fig. 4 (top), and a trend is seen where storage in WMOII solution has lower $\mathrm{SCr}$ and potassium than storage in HTK solution. This trend becomes clear at 24-h storage (Fig. 4, middle), where sustained elevation of $\mathrm{SCr}$ is observe in HTK storage, whereas storage in WMO-II is lower. Finally, and most importantly, prolonged storage of the ex vivo kidneys for $48 \mathrm{~h}$ results in clear difference between the two organ preservation solutions. WMO-II significantly reduces $\mathrm{SCr}$ and serum potassium compared to HTK solution, indicating that WMO-II solution may be improving CIT time over previous preservation solutions. Since we have a limited number of dogs used in the present study, other days or storage times did not reach significance.

This study showed that WMO-II is more effective at clearing red blood cells from the microvasculature of perfused kidneys. Although the auto transplantation model used in this study is excellent for assessing the efficacy of perfusion and maintenance of kidney heath, it does not allow for the assessment of graft rejection or tissue damage caused by an immune response. We believe that by improving the clearance of the microvasculature, there will also be a reduction in white blood cells from the donor, reducing damage caused by the recipient's immune system to result in a reduction of DFG and PNF, however, this must be tested in future experiments. Although the WMO-II solution is a clear improvement upon perfusion solutions that are currently standard in the clinical setting, we also look to investigate its effectiveness in prolonging warm ischemia time in the future, potentially reducing the damage caused by placing tissues on ice and further improving tissue survival and function for kidney transplantation.

\section{Materials and methods WMO-II solution}

The WMO-II solution was designed by the Institute of Organ Transplantation and the Pharmacy Department of Tongji Hospital, Tongji Medical College, Huazhong University of Science and Technology (Table 1). The solution used for this study was manufactured by Huaren Pharmaceutical Co. Ltd., Qingdao, China, with our permission. The product consists of two connected inner bags and an over pouch. The inner bags are separated into Chamber $A$ and Chamber B by a peel-able seal that can be opened with a moderate squeeze to mix solutions $\mathrm{A}$ and $\mathrm{B}$ (Additional file 1: Figure S1). An oxygen absorber is placed between the inner bag and the over pouch. Based on the components of solutions A and B, the WMO-II solution remains stable when stored at room temperature or $4{ }^{\circ} \mathrm{C}$. Before use, the solution is mixed and cooled to $4{ }^{\circ} \mathrm{C}$.

\section{Animals}

All procedures involving animals in this study were performed in accordance with the guidelines for animal experiments of the Chinese Council on Animal Care, and were approved by the Institutional Animal Care and Use Committee of the Huazhong University of Science and Technology. The adult male beagle dogs were purchased from the Experimental Animal Center of Tongji Medical College. The animals, weighing $10.0 \pm 1.8 \mathrm{~kg}$ (mean $\pm \mathrm{SD})$, were housed in metabolic cages and allowed to acclimatize to their surroundings for 1 week before the surgery. All animals were fasted $12 \mathrm{~h}$ prior to the surgery.

\section{Experimental design}

An auto-transplantation model was used to test the renal protective effect of the WMO-II solution. The HTK solution was used as a control solution because it is another low-viscosity perfusate that is already approved for clinical use. The animals were randomly assigned to groups designated by preservation solution (WMO-II and HTK) and cold storage time [12 h $(\mathrm{n}=5), 24 \mathrm{~h}(\mathrm{n}=10)$, and $48 \mathrm{~h}(\mathrm{n}=10)]$. The recipient animals were monitored for up to 10 days to assess kidney function by serum creatinine $(\mathrm{SCr})$ and potassium $\left(\mathrm{K}^{+}\right)$concentrations.

Another series of experiments with animals analyzed the protective mechanisms of the WMO-II. The left and right kidneys were removed for flushing and ex vivo storage (left by WMO-II, and right by HTK). After kidney 


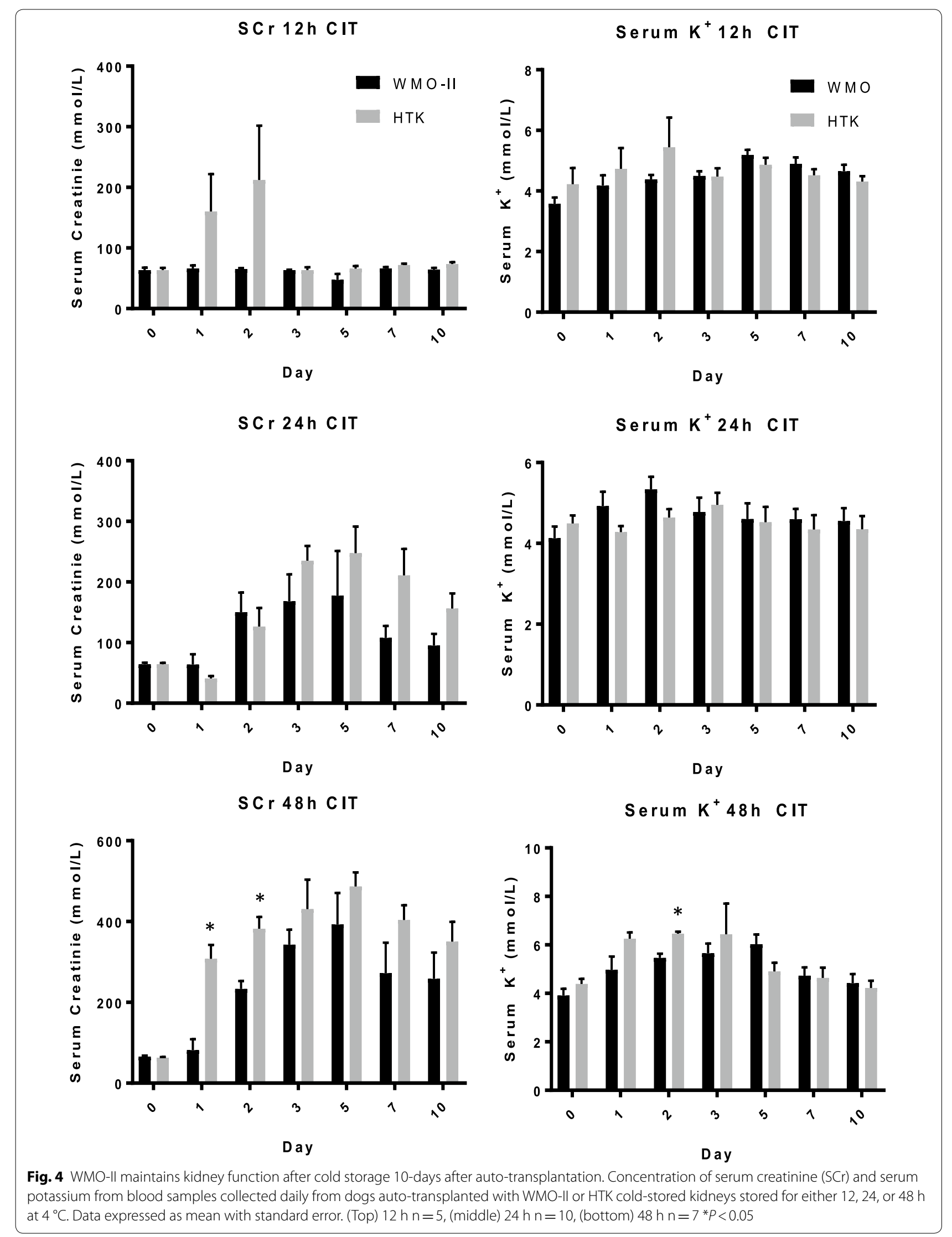


procurement, the donors were euthanized. The kidneys of each animal were designated into two groups: WMOII $(0,12,24$ and $48 \mathrm{~h})$ groups and HTK $(0,12,24$ and $48 \mathrm{~h}$ ) groups ( $\mathrm{n}=6$ kidneys per group). At the designed time-points of cold storage, the kidneys were prepared for glomerular microvasculature perfusion analysis, pathological evaluation, transmission electron microscopic analysis, and apoptotic analysis.

\section{Kidney procurement and auto-transplantation}

The canine auto-transplantation model is already established. Briefly, animals were heparinized with $50 \mathrm{U} / \mathrm{kg}$ of heparin, and the left kidney was collected as the donor kidney by cutting the ureter at the iliac vessel and transecting the renal artery and vein from the aorta and vena cava. Kidneys were flushed with $150 \mathrm{~mL}$ of the WMOII solution or the HTK solution at $4{ }^{\circ} \mathrm{C}$ via the artery for 5 min or until the effluent ran clear. The kidney was stored in cold solution at $4{ }^{\circ} \mathrm{C}$ for 12,24 , or $48 \mathrm{~h}$. After surgery, the animals were given Ringer's solution supplemented with $10 \%$ glucose as well as food and water up to $12 \mathrm{~h}$ before the auto-transplantation surgery.

For auto-transplantation, the animals were re-anesthetized at the time corresponding to the experimental cold storage time. The kidney artery was anastomosed end-toend to the external iliac artery, and the kidney vein was anastomosed end-to-side to the external iliac vein. After ureterocystostomy, right nephrectomy was performed to examine only the effects of the transplanted kidney. At 10 days post operation, animals were intravenously euthanized with an overdose of pentobarbital $(100 \mathrm{mg} / \mathrm{kg})$ and the auto-grafts were collected for further analysis.

\section{Glomerular microvasculature perfusion analysis}

Six kidneys from the WMO-II $(0 \mathrm{~h})$ group and HTK $(0 \mathrm{~h})$ group were analyzed. Each kidney was prepared in two sections $(1 \mathrm{~cm} \times 1 \mathrm{~cm})$ for hematoxylin and eosin $(H \& E)$ staining. All glomeruli in each section were evaluated under $200 \times$ magnification and the average number of red blood cells retained in a single glomerulus in each group was counted.

\section{Transmission electron microscopic analysis}

Tissues were immediately immersed in $2.5 \%$ glutaraldehyde for $2 \mathrm{~h}$. After being washed three times in PBS (pH 7.4), the tissue was post fixed in $1 \%$ osmium tetroxide for $30 \mathrm{~min}$, dehydrated through graded alcohol and acetone, and embedded in Epon 812. Ultrathin sections were stained with uranyl acetate and lead citrate and imaged with a Philips CM10 transmission electron microscope (FEI, Philips, Eindhoven, Netherlands).

\section{Apoptosis analysis}

Apoptosis was detected by terminal deoxynucleotidyl transferase-mediated dUTP-biotin nick end labeling (TUNEL) assay with ApopTag technology (Millipore, Billerica, MA, USA) according to the manufacturer's instructions. Apoptosis was quantified by counting the number of positive cells per $200 \times$ field.

\section{Western blot analysis}

Kidney tissue was homogenized in $1 \times$ RIPA buffer (Millipore, Billerica, MA) with $2 \%$ Halt Protease Inhibitors and 1\% Halt Phosphatase Inhibitors (Pierce Biotechnology, Rockford, IL, USA). The lysates were spun down at $11,000 \mathrm{~g}$ for $15 \mathrm{~min}$ and the protein concentrations of the supernatant were measured using the Bradford Method (Bio-Rad, Hercules, CA). Protein expression of Fas-mediated (Fas, dilution, 1:1000, BD Biosciences San Jose, CA), mitochondrion-mediated (Caspase-9, dilution, 1:1000, BD Biosciences San Jose, CA) and endoplasmic reticulum stress (ERS)-mediated (BiP, dilution, 1:1000; Chop, dilution, 1:2000 and Caspase-12, dilution, 1:2000) (BD Biosciences San Jose, CA) apoptotic pathways were examined. Band densities were determined using AlphaEaseFC ${ }^{\mathrm{TM}}$ (Alpha Innotech) software and normalized to corresponding $\beta$-actin signal.

\section{Kidney function evaluation}

Blood samples were drawn before the surgery and every $24 \mathrm{~h}$ post-transplantation. Samples were evaluated for serum levels of $\mathrm{SCr}$ and potassium $\left(\mathrm{K}^{+}\right)$. The specific procedures were according to the kits protocol (Sigma Diagnostics Co. St. Louis, MO).

\section{Statistical analysis}

Statistical analysis was performed using SPSS (version 17.0; SPSS Inc., Chicago, IL, USA). Quantitative data were presented as mean \pm SEM. Statistical differences between groups at each time point were tested by threeway or two-way analysis of variance (ANOVA), followed by a Bonferroni correction. Mann-Whitney $U$-test was used for non-normally distributed data, and unpaired two-tailed Student's $t$-test was performed for normally distributed data. $P<0.05$ was considered statistically significant.

\section{Additional file}

Additional file 1: Figure S1. WMO-II solution: The product consists of chamber $A$ and chamber $B$ separated by a peelable seal that can be opened with a moderate squeeze to mix for use. 


\section{Abbreviations}

DGF: delayed graft function; PNF: primary nonfunction; UW: University of Wisconsin; HTK: histidine-tryptophan-ketoglutarate; WMO-II: Wuhan Medical College organ preservation solution-II; CP: centi-Poise; SCr: serum creatinine; CIT: cold ischemia time.

\section{Authors' contributions}

NQG and ZSC designed the research. SW and XZL performed almost all molecular biological and biochemical experiments. KG, HZ, JJM and TT analyzed the data and discussed the results. HYJ, JGF and GD preceded the preliminary experiments. SW, HBS and HHW performed almost all animal surgeries. HG performed almost all pathological evaluation experiment. CSM and $\mathrm{PZ}$ provided continuous support and conceptual advice for this study. SW, KG, JM and NQG wrote the paper. All authors read and approved the final manuscript.

\section{Author details}

${ }^{1}$ Institute of Organ Transplantation, Key Laboratory of the Ministry of Health and the Ministry of Education, Tongji Hospital, Tongji Medical College, Huazhong University of Science and Technology, Wuhan 430030, China.

${ }^{2}$ Department of Surgery, Davis Heart and Lung Research Institute, The Ohio State University, Columbus, $\mathrm{OH}$ 43210, USA. ${ }^{3}$ Department of Molecular and Cellular Biochemistry, The Ohio State University, Columbus, $\mathrm{OH} 43210$, USA. ${ }^{4}$ Department of Pharmacy, Tongji Hospital, Tongji Medical College, Huazhong University of Science and Technology, Wuhan 430030, China.

\section{Acknowledgements}

None.

\section{Competing interests}

The authors declare that they have no competing interests.

\section{Availability of data and materials}

The datasets used and/or analyzed during the current study are available from the corresponding author on reasonable request.

\section{Consent for publication}

Not applicable.

\section{Ethics approval and consent to participate}

All procedures involving animals in this study were performed in accordance with the guidelines for animal experiments of the Chinese Council on Animal Care, and were approved by the Institutional Animal Care and Use Committee of the Huazhong University of Science and Technology.

\section{Funding}

This work was supported by Grants to NQ Gong from the National Natural Science Foundation of China (No. 81570678), to NQ Gong from the Clinical
Research Physician Program of Tongji Medical College, HUST, to NQ Gong from Major State Basic Research Development Program of China (NO. 2013CB530803, 973), to CS Ming from the National High-Tech Research and Development Program (Program 863) of the Ministry of Science and Technology of China (2012AA021010), and to ZS Chen from the Translational Grant of Tongji Hospital.

\section{Publisher's Note}

Springer Nature remains neutral with regard to jurisdictional claims in published maps and institutional affiliations.

Received: 14 March 2018 Accepted: 30 March 2018

Published online: 10 April 2018

\section{References}

1. Ponticelli C. Ischaemia-reperfusion injury: a major protagonist in kidney transplantation. Nephrol Dial Transplant. 2014;29:1134-40.

2. Clemens MG, McDonagh PF, Chaudry $\mathrm{H}$, et al. Hepatic microcirculatory failure after ischemia and reperfusion: improvement with ATP- $\mathrm{MgCl}_{2}$ treatment. Am J Physiol. 1985;248:H804-11.

3. Tojimbara T, Wicomb WN, Garcia-Kennedy R, et al. Liver transplantation from non-heart beating donors in rats: influence of viscosity and temperature of initial flushing solutions on graft function. Liver Transpl Surg. 1997;3:39-45.

4. Bond M, Pitt M, Akoh J, et al. The effectiveness and cost-effectiveness of methods of storing donated kidneys from deceased donors: a systematic review and economic model. Health Technol Assess. 2009;13:1-156.

5. Stewart ZA, Lonze BE, Warren DS, et al. Histidine-tryptophan-ketoglutarate $(H T K)$ is associated with reduced graft survival of deceased donor kidney transplants. Am J Transplant. 2009;9:1048-54.

6. Irish WD, Ilsley JN, Schnitzler MA, et al. A risk prediction model for delayed graft function in the current era of deceased donor renal transplantation. Am J Transplant. 2010;10(10):2279-86.

7. Rauen U, Kerkweg U, de Groot H. Iron-dependent vs. iron-independent cold-induced injury to cultured rat hepatocytes: a comparative study in physiological media and organ preservation solutions. Cryobiology. 2007:54(1):77-86.

8. Haskó G, Cronstein BN. Adenosine: an endogenous regulator of innate immunity. Trends Immunol. 2004;25(1):33-9.

9. Sheffner AL, Medler EM, Jacobs LW, et al. The in vitro reduction in viscosity of human tracheobronchial secretions by acetylcysteine. Am Rev Respir Dis. 1964;90:721-9.

10. Lewis SL. Medical surgical nursing. 8th ed. London: Elsevier Health Sciences; 2010.
Ready to submit your research? Choose BMC and benefit from:

- fast, convenient online submission

- thorough peer review by experienced researchers in your field

- rapid publication on acceptance

- support for research data, including large and complex data types

- gold Open Access which fosters wider collaboration and increased citations

- maximum visibility for your research: over 100M website views per year

At BMC, research is always in progress.

Learn more biomedcentral.com/submissions 